generational reappraisal of architecture Cedric Price's ‘calculated uncertainty’ illusory plastic spaces of Hagia Sophia

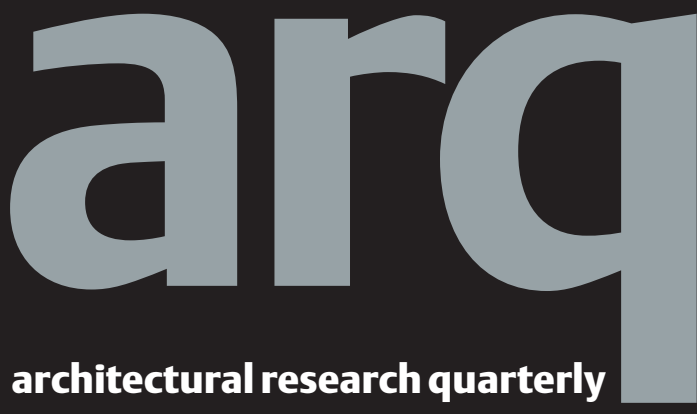




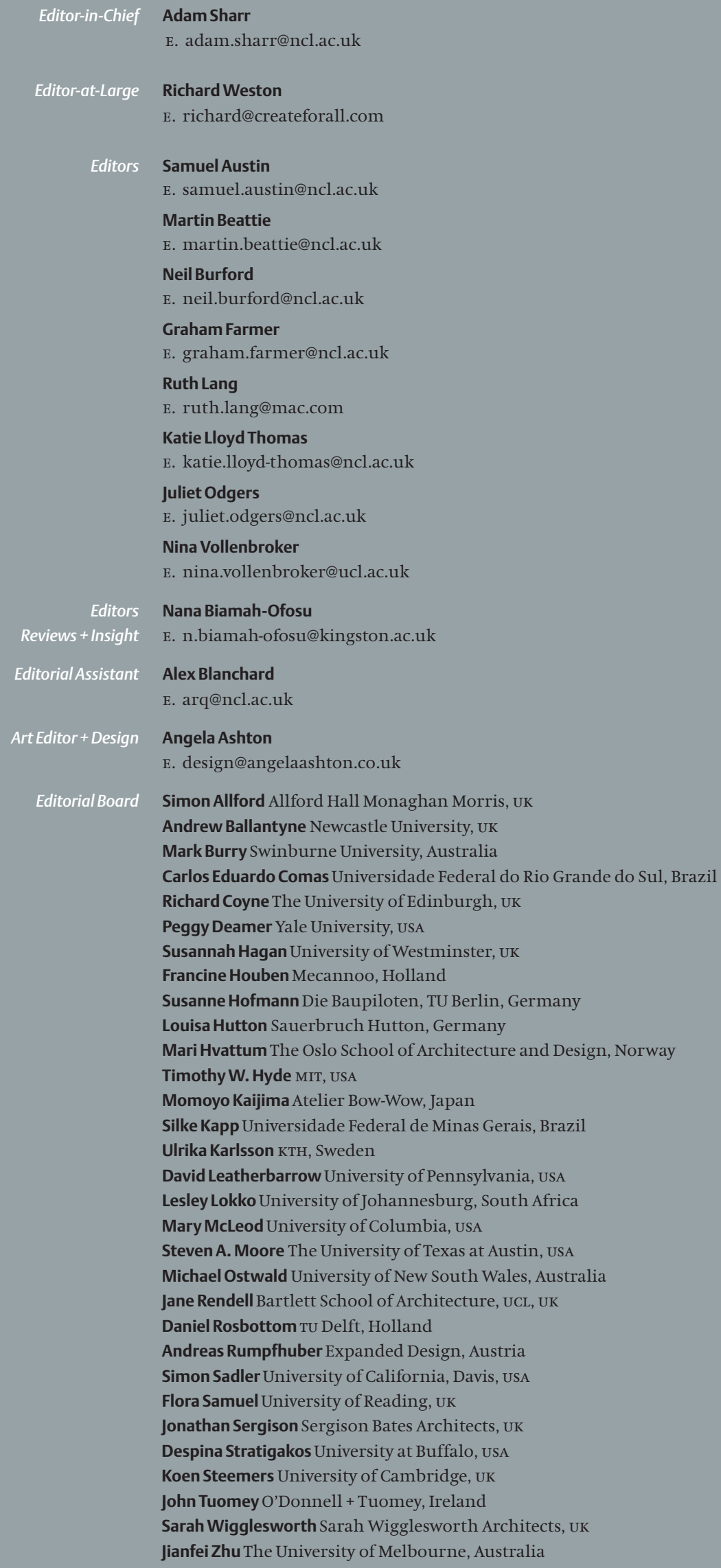

Editorial Board Simon Allford Allford Hall Monaghan Morris, UK Andrew Ballantyne Newcastle University, UK Mark Burry Swinburne University, Australia Carlos Eduardo Comas Universidade Federal do Rio Grande do Sul, Brazil Richard Coyne The University of Edinburgh, UK Peggy Deamer Yale University, USA

Susannah Hagan University of Westminster, UK Francine Houben Mecannoo, Holland

Susanne Hofmann Die Baupiloten, TU Berlin, Germany Louisa Hutton Sauerbruch Hutton, Germany

Mari Hvattum The Oslo School of Architecture and Design, Norway Timothy W. Hyde MIT, USA

Momoyo Kaijima Atelier Bow-Wow, Japan

Silke Kapp Universidade Federal de Minas Gerais, Brazil

Ulrika Karlsson Ктн, Sweden

David Leatherbarrow University of Pennsylvania, USA Lesley Lokko University of Johannesburg, South Africa Mary McLeod University of Columbia, USA

Steven A. Moore The University of Texas at Austin, USA Michael Ostwald University of New South Wales, Australia Jane Rendell Bartlett School of Architecture, UCL, UK Daniel Rosbottom tu Delft, Holland Andreas Rumpfhuber Expanded Design, Austria Simon Sadler University of California, Davis, USA Flora Samuel University of Reading, UK Jonathan Sergison Sergison Bates Architects, UK Despina Stratigakos University at Buffalo, USA Koen Steemers University of Cambridge, UK John Tuomey O'Donnell + Tuomey, Ireland Sarah Wigglesworth Sarah Wigglesworth Architects, UK Jianfei Zhu The University of Melbourne, Australia 
COVER

David Walker offers

visual study of Hagia

Sophia, defining illusory

plastic space before

further developing

historical literary and

visual insights.

Seepp. 145-176.

leader
criticism
theory

history

urbanism

Urban cloverleaves: origin, aesthetics, and contradictions of the Slussen, Stockholma Álvaro Clua Uceda analyses the urban cloverleaf interchange, with reference to the Slussen in Stockholm, designed by Tage William-Olsson and Gösta Lundborg, 1929-35.

reviews

\section{Generational reappraisal}

108

ing Calculated Uncertainty: Cedric Price's Interaction Centre Marcel Aragüez unfolds Cedric Price's notion of Calculated Uncertainty through a meticulous analysis of Price's Interaction Centre, revealing inherent tensions between his discursive production and built output.

125 Making space for degenerate thinking: revaluing architecture with Friedrich Nietzsche Simon Weir and Glen Hill examine how the experience of extraordinarily hyperperceptive individuals could provide insight into the qualities necessary for the philosopher Friedrich Nietzsche's 'Architecture for the Perceptive'.

Mechanistic plan and urban mass: two contexts of efficient wedding halls in Turkey Emre Altürk re-thinks the layout of Turkey's wedding halls from the mid-twentieth century, showing how architects deployed modernist spatial optimisation techniques to attain efficiency in the face of a rapidly growing urban population.

145 The illusory plastic space of Hagia Sophia David Walker offers an examination of the intrinsic visual-spatial characteristics of Hagia Sophia, the nave as optical space, the antiphonal spaces created by double structure, and phases of illusory plastic space.

\section{Drawing Parallels}

Konstantinos Avramidis

194 Superstudio Migrazioni

Aleks Catina 


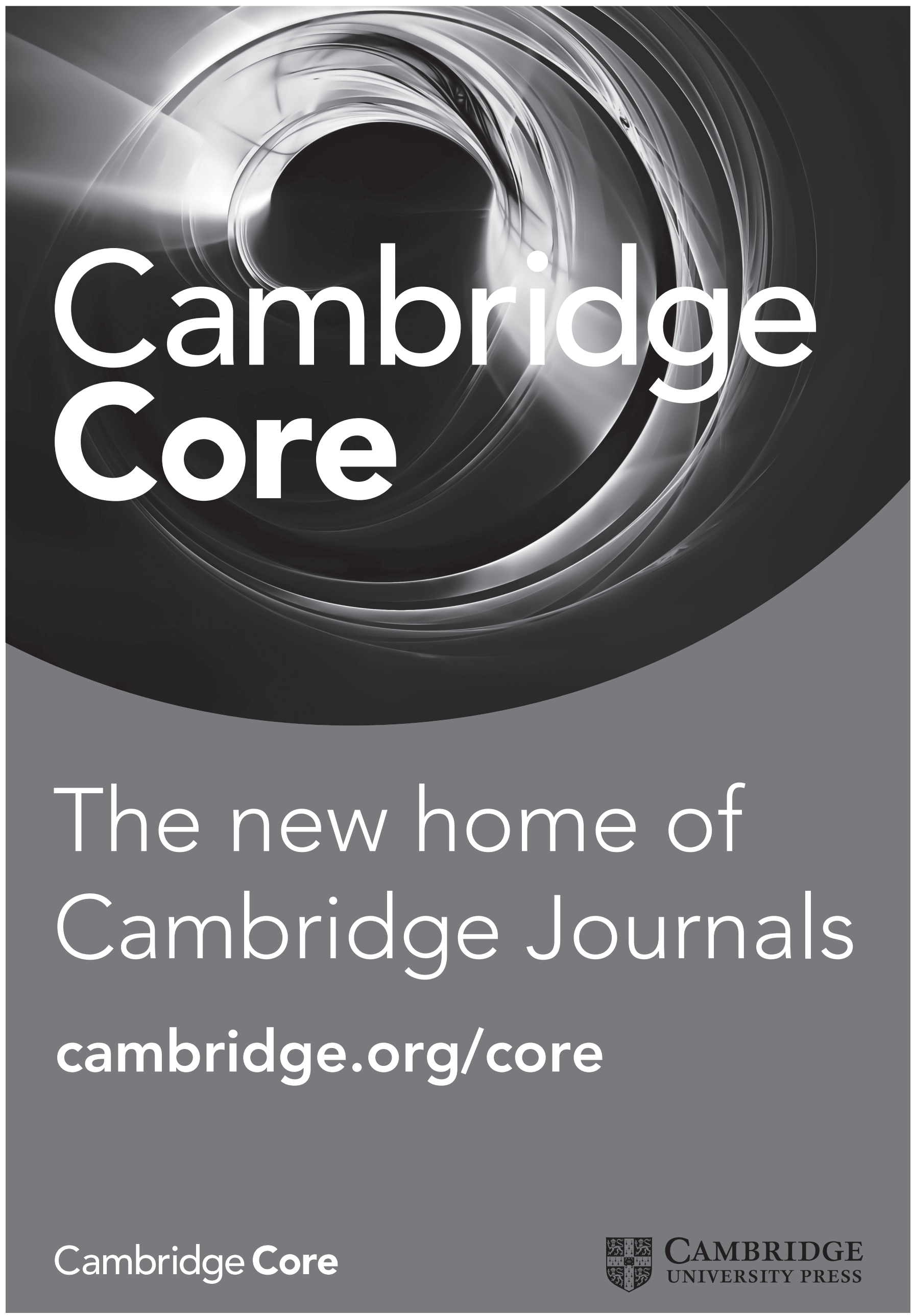

